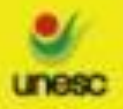

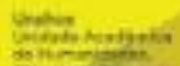

unesc

atoming

\title{
PARTICIPAÇÃO E REAÇÃO DOS PAIS NO PERIODO DE ADAPTAÇÃO NA INSERÇÃO DE SEUS FILHOS NA CRECHE
}

\section{PARTICIPATION AND REACTION OF THE PARENTS IN THE PERIOD OF ADAPTATION IN THE INSERTION OF THEIR CHILDREN IN THE CRECHE}

\section{Tainara Maravai ${ }^{1}$}

Cibele da Silva Lucion²

\begin{abstract}
RESUMO: O presente artigo discute sobre a importância do período da adaptação da criança na creche, visando conhecer a participação e reação dos pais nesse processo. Estudar este tema poderá ajudar muitos pais que se encontram nessa situação de despreparo com a adaptação, bem como contribuir com as instituições de ensino. Desta forma, o objetivo geral consistiu-se em analisar a participação e reação dos pais no período de adaptação de seus filhos na creche. Para tal, os objetivos específicos foram: compreender a trajetória histórica da Educação Infantil, verificar a finalidade da Educação Infantil na legislação, identificar as dificuldades enfrentadas pelos pais ao deixarem seus filhos na creche, apontar como os pais podem auxiliar na adaptação de seus filhos e discutir a importância da adaptação escolar para a aprendizagem/desenvolvimento da criança na creche. Para a realização desta pesquisa, utilizou-se a abordagem qualitativa e uma pesquisa de campo, em que participaram deste estudo turmas do berçário I e II e infantil I, com familiares de crianças de zero a três anos de idade, matriculadas numa escola particular no município de Criciúma/SC. Os resultados obtidos ressaltam que muitos pais acabam interferindo na adaptação dos filhos, por meio de suas reações e sentimentos de insegurança. Porém, se estes tiverem uma boa relação com a creche por meio de diálogos frequentes, em que esta atua respondendo e acolhendo as dúvidas dos pais, a adaptação da criança tende a ocorrer de forma mais tranquila, favorecendo na sua aprendizagem e permanência saudável na instituição.
\end{abstract}

PALAVRAS CHAVE: Adaptação na creche. Pais. Participação. Reações.

ABSTRACT: The present article discusses the importance of the period of adaptation of the child in the day care center, aiming to know the participation and reaction of the parents in this process. Studying this topic may help many parents who find themselves in this situation of unpreparedness with adaptation, and thus also contribute to educational institutions. Thus, the general objective was to analyze the participation and reaction of the parents in the period

\footnotetext{
${ }^{1}$ Graduada em Pedagogia da Universidade do Extremo Sul Catarinense, UNESC. E-mail: tainaramaravai2@gmail.com

${ }^{2}$ Mestre em Educação. Psicóloga. Psicopedagoga. Docente da UNESC. E-mail: cibelelucion@ unesc.net Saberes Pedagógicos, Criciúma, v. 4, nº1, janeiro/abril 2020.-Curso de Pedagogia- UNESC
} 


\section{SABERES PEDAGÓGICOS}

Revista do Curso de Graduaçāo de Pedagogia - Unesc

ISSN 2526-4559

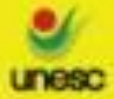

tanting

of adaptation of their children in the day care center, for that the specific objectives were: to understand the historical trajectory of Early Childhood Education, verify the purpose of Early Childhood Education in legislation, identify the difficulties faced by parents when leaving their children in the day care, understand how parents can assist in the adaptation of their children and discuss the importance of school adaptation to the child's learning / development in day care. In order to carry out this research, we used the qualitative approach and a field research, in which nursery classes I and II and infant I participated in this study, with relatives of children from zero to three years of age enrolled in a private school in the municipality of Criciúma / SC. The results obtained highlight that many parents end up interfering in the children's adaptation through their reactions and feelings of insecurity. However, if the children have a good relationship with the day care center through frequent dialogues, in which the child responds and accepts the doubts of the parents, the child's adaptation tends to occur more calmly, favoring his or her learning and staying healthy in the institution.

KEYWORDS: School adaptation. Parents. Participation. Reactions.

\section{INTRODUÇÃO}

A pesquisa "Participação e reação dos pais no período de adaptação na inserção de seus filhos na creche" surgiu por meio das observações realizadas nos dois anos de estágio não obrigatório na Educação Infantil no curso de Pedagogia com crianças de dois a três anos de idade em um Centro de Educação Infantil Municipal. Nesse estágio, notou-se que a adaptação é um dos processos mais importantes que ocorre na creche, pois se ela não acontecer da melhor forma possível, pode afetar a aprendizagem, o relacionamento e a permanência da criança na instituição. Fatores como os pais e filhos não conhecerem o professor e o ambiente escolar, previamente a matrícula, podem dificultar ainda mais essa adaptação, além de que o processo de separação entre os pais e filhos muitas vezes é doloroso.

Sabe-se que a creche de escolas públicas é um atendimento gratuito para crianças de zero a três anos de idade, disponibilizado pelo Estado, mas não é obrigatório. A educação básica é obrigatória somente a partir dos quatro anos, e quem atende a esta idade é a préescola. Então, a creche surgiu como um atendimento para os pais que realmente necessitavam deixar seus filhos na escola, precisando, assim, confiar nos professores e na instituição.

A relação entre pais e creche é um assunto muito relevante e muitas vezes não é dado a sua devida importância. Por este motivo, resolveu-se pesquisar este tema, pois 
entendendo a postura dos pais nesse processo de adaptação será possível conhecer de que maneira trabalhar melhor essa inserção.

Por este motivo, surgiu o seguinte questionamento: quais as reações dos pais durante o período de inserção dos seus filhos na creche? E para tentar responder a esse problema de pesquisa, tem-se como objetivo geral: analisar a participação e reação dos pais no período de adaptação de seus filhos na creche. E, para atingir esse objetivo, foram elaborados os objetivos específicos: compreender a trajetória histórica da Educação Infantil; verificar a finalidade da Educação Infantil na legislação; identificar as dificuldades enfrentadas pelos pais ao deixarem seus filhos na creche; apontar como os pais podem auxiliar na adaptação de seus filhos; discutir a importância da adaptação escolar para a aprendizagem/desenvolvimento da criança na creche.

Este artigo foi organizado de maneira em que no primeiro momento é apresentada a fundamentação teórica, contendo os principais autores que abordam a temática referente a adaptação na creche, assim como, o comportamento dos pais nesses período. Além disso, também os fatores históricos vinculados a concepção da infância e legislação em relação ao direito da inserção destas na Educação Infantil. Posteriormente, apresenta-se a metodologia utilizada nesta pesquisa, assim como, a análise contendo os relatos e a descrição de acordo com o que se encontrou na pesquisa, relacionando com os autores utilizados. Por fim, a conclusão, é composta por sugestão e as principais aprendizagens e considerações que esta pesquisa possibilitou.

\section{TRAJETÓRIA HISTÓRICA DA EDUCAÇÃO INFANTIL}

Ao se falar em Educação Infantil momentaneamente isso lembra as crianças, elas geralmente trazem lembranças de suas vivências, brincadeiras, alegrias, e infância, mas se sabe que nem sempre foi assim. Por este motivo, faz-se necessário entender como foi a trajetória histórica da concepção do ser criança e, em seguida, sobre a história da Educação Infantil.

Antigamente não se tinha uma concepção de criança como uma etapa particular, tudo que elas aprendiam era porque sempre estavam no meio dos adultos, por conviverem Saberes Pedagógicos, Criciúma, v. 4, nº1, janeiro/abril 2020.- Curso de Pedagogia- UNESC 
sempre com eles, eram tratadas como espécie de mini-adultos. De acordo com Ariès (1981, p. 10):

\begin{abstract}
[...] essa sociedade via mal a criança, e pior ainda o adolescente. A duração da infância era reduzida a seu período mais frágil, enquanto o filhote do homem ainda não conseguia bastar-se; a criança então, mal adquiria algum desembaraço físico, era logo misturada aos adultos, e partilhava de seus trabalhos e jogos. De criancinha pequena, ela se transformava imediatamente em homem jovem, sem passar pelas etapas da juventude [...].
\end{abstract}

Desta forma, a criança era vista como um mini-adulto e por isso não usufruía de sua infância, já que não havia um olhar atento a ela. Essa passagem da infância vista pela família e pela sociedade era tão curta e tão desprezível, que não havia necessidade de gastar tempo e afetividade com elas (ARIÈS, 1981).

Foi só a partir do fim do século XVII que as ideias começaram a mudar em relação a esse olhar sobre a criança. Elas passaram a frequentar espaços diferentes, não se misturando mais aos adultos. A criança começou a aprender e a viver a infância de uma forma distinta. Ariès (1981, p. 65) diz que nesse século “[...] os retratos de crianças sozinhas se tornaram numerosos e comuns. Foi também nesse século que os retratos de família, muito mais antigos, tenderam a se organizar em torno da criança, que se tornou o centro da composição."

Pode-se notar que foi a partir desse século que a criança foi introduzida no centro do grupo familiar, ou seja, quando ela começou a ser notada. Assim, surgiu a descoberta da infância e também se deu início a uma função dentro da família, que até então não se tinha em relação a ela, o gesto de afetividade e os cuidados adaptados a sua faixa etária, não sendo mais tratada somente como uma espécie de mini-adulto. Com isso, a criança passou a ser valorizada e respeitada por sua família e sociedade, despertando uma preocupação com elas e principalmente com a sua educação.

Ao resgatarmos a trajetória histórica do atendimento oferecido à criança de zero a seis anos no Brasil, procuramos relacioná-la com as mudanças ocorridas nos diversos setores sociais, principalmente no campo educacional. [...] Entendemos que o surgimento das instituições direcionadas à educação da criança pequena esclarece a história de várias modificações efetuadas em nosso contexto social, como a 


\section{SABERES PEDAGÓGICOS}

Revista do Curso de Graduaçāo de Pedagogia - Unesc

ISSN 2526-4559

organização familiar e do mercado de trabalho, especialmente, o feminino. (FARIAS, 2005, p. 33).

As mulheres começaram a se inserir no mercado de trabalho para conseguirem aumentar a renda familiar dentro de casa, bem como pela busca de realização pessoal. Por estes motivos, teve-se a preocupação e necessidade de um lugar adequado aonde pudessem deixar os seus filhos, enquanto as mães estivessem trabalhando. Assim, as creches surgiram: “[...] no início do século XX, no Brasil acompanhando a estruturação do capitalismo, a crescente urbanização e a necessidade de reprodução de força de trabalho composta por seres capazes, nutridos, higiênicos e sem doenças.” (HADDAD, 2002, p. 24). Portanto, a creche passou a ter como finalidade cuidar dos filhos desses pais e mães que estivessem trabalhando e que não tinham onde deixá-los.

Atualmente, a opção de colocar o filho na creche vai além das necessidades vinculadas ao trabalho dos pais. Muitos acabam colocando a criança na escola para que haja socialização e para que ela se desenvolva com mais qualidade. Rapoport (2017, p. 73) fala que uma das explicações possíveis é que eles “[...] acreditam que a escolha pela instituição se constitua em um bom ambiente para socialização e educação do seu filho."

Neste aspecto, Papalia e Feldman (2013) citam que o fato das mães trabalharem, e as crianças passarem maior tempo na escola não é considerado prejudicial ao desenvolvimento, o que também foi um olhar historicamente desconstruído no sentido de que estar em casa e não frequentar a creche seria o mais adequado. Estes autores ainda comentam que para a saúde psicológica da criança é mais importante a qualidade do tempo que os pais disponibilizam a eles do que a quantidade. Então, para que os direitos das crianças de permanecerem nas creches fossem garantidos, ao longo dos anos, foram surgindo leis para apoiar essa permanência dentro da escola. Por isso, na sequência, apresentar-se-á como a Educação Infantil é assegurada na legislação, pois historicamente sentiu-se a necessidade de garantir em forma de leis os direitos das crianças.

\subsection{Educação Infantil na Legislação}

Saberes Pedagógicos, Criciúma, v. 4, nº 1, janeiro/abril 2020.- Curso de Pedagogia- UNESC 
A Educação Infantil abrange a creche e a pré-escola, que é reconhecida pela LDB 9.394/96 como a primeira etapa da educação básica.

A Lei de Diretrizes e Bases da Educação Nacional (LDB) nº 9.394/96 diz que a Educação Infantil tem por finalidade "o desenvolvimento integral da criança de até 5 (cinco) anos, em seus aspectos físico, psicológico, intelectual e social, complementando a ação da família e da comunidade.” (BRASIL, 1996, p. 14).

Esta lei assegura que a creche é um direito das crianças, uma opção da família, e dever do Estado com a educação, disponibilizar vagas em escolas públicas. Já a pré-escola, é obrigatória e também dever de o Estado disponibilizar vagas para essas crianças (BRASIL, 1996).

Ainda em se tratando dos documentos que norteiam a Educação Infantil, têm-se também a Base Nacional Comum Curricular que divide a Educação Infantil em três grupos de faixas etárias, sendo a creche, crianças de zero a 1 ano e 6 meses e crianças de 1 ano e 7 meses a 3 anos e 11 meses, e a pré-escola, crianças de 4 anos a 5 anos e 11 meses de idade. (BRASIL, 2016). Portanto, pode-se notar que existem leis que amparam a Educação Infantil e que ela é de direito das crianças. Elas garantem os direitos das crianças dentro da escola e também ressaltam a importância da creche e da pré-escola no processo de desenvolvimento e aprendizagem da criança. 


\section{ADAPTAÇÃO DA CRIANÇA NA CRECHE}

Adaptação escolar nem sempre é um período fácil para as crianças, por se tratar de um ambiente totalmente novo e diferente do que elas estão acostumadas, então suas reações são geralmente de curiosidade ou estranheza, mas, sabe-se também que nenhuma criança é igual a outra, portanto suas reações frente a este novo mundo podem ocorrer de maneiras distintas. "Algumas ficam agitadas e correm pela sala empurrando, cutucando, tocando e olhando. Outras parecem estar pouco à vontade; se retraem e exploram com seus olhos, enquanto seus corpos permanecem inertes." (BALABAN, 1988, p. 15).

Papalia e Feldman (2013) também falam que cada criança é diferente uma da outra e para justificar isso elas apresentam três tipos de comportamentos: o temperamento fácil, o temperamento difícil e o de aquecimento lento. O primeiro se trata de uma criança geralmente feliz e que sempre aceita as novas experiências, o segundo temperamento demostra uma criança mais irritadiça e resistente às novas experiências. Por fim, a terceira criança de aquecimento lento é mais suave e tranquila, porém ela demora mais para reagir às novas experiências.

Isso ocorre porque as crianças não são iguais em diversos aspectos, assim reagem de formas distintas. As crianças ainda podem expressar outros sentimentos que também são considerados comuns nesse processo de adaptação. Segundo Rapoport e Piccinini (2001, p. 86), as crianças podem manifestar reações diferenciadas, tais como:

[...] o choro é comum entre crianças durante este período, tanto na chegada quando a criança é deixada na creche pelos pais, como na saída, quando os pais retornam para buscá-la. Mas o choro não é a única reação de perturbação possível por parte da criança. Existem várias outras manifestações como, por exemplo, gritos, mal humor, bater, deitar no chão, passividade, apatia, resistência à alimentação ou ao sono e comportamentos regressivos.

Pode-se notar que as crianças se manifestam de diversas formas, então cada adaptação será diferente da outra. Lembrando ainda que essa inserção não tem um tempo determinado, pois tudo vai depender do modo de agir de cada criança, por isso ela deve ocorrer da maneira mais tranquila possível (WORST, 2016).

Saberes Pedagógicos, Criciúma, v. 4, nº 1, janeiro/abril 2020.- Curso de Pedagogia- UNESC 
Para que essa adaptação ocorra da melhor forma para todos, tanto para as crianças, como para seus pais e professores, primeiramente a creche deve estar preparada para recebêla. Isso pode ocorrer por meio do que Worst (2016) chama de estratégias, ou seja, a creche pode utilizar vários métodos para facilitar essa inserção. Uma das estratégias é a presença dos pais na creche durante os primeiros dias no processo de adaptação de seus filhos; e, outra estratégia é que se pode conduzir deixando aos poucos essa criança na instituição e com o passar dos dias ir aumentando sua permanência, monitorando os horários de chegada e saída, conforme a criança vai se adaptando.

Com esses tipos de estratégias, a segurança e confiança da criança com o professor e a creche vão aumentando gradativamente, tornando-se, assim, uma maneira de facilitar esse processo. "Quando as crianças vêem o professor com mais confiança, elas frequentemente começam a expandir os seus relacionamentos até o ambiente físico e até as outras crianças de maneira mais aberta.” (BALABAN, 1988, p. 16).

Então, a creche precisa estar preparada para receber a família, entendendo que a criança estará num ambiente totalmente novo e desconhecido. Para que tudo aconteça da forma mais natural possível é imprescindível que exista uma aliança entre os pais e a creche, e que essa aliança permaneça, pois se o processo de adaptação da criança ocorrer de forma harmônica entre a creche e os pais, terá maiores chances para dar certo, lembrando que isso fortalecerá o processo de ensino e aprendizagem da criança.

\section{O PAPEL DOS PAIS NA ADAPTAÇÃO: PRINCIPAIS DESAFIOS}

Colocar um filho na creche muitas vezes não é uma escolha muito fácil para os pais, porém é uma necessidade e eles precisam deixar seus filhos sobre os cuidados de um profissional. Desta forma, em alguns casos, a adaptação é pior para os pais do que para seus próprios filhos, pois esse elo será rompido com a separação deles na creche.

A separação afeta as crianças. Afeta aos pais. Faz brotar sentimentos nos professores. O início da vida escolar pode ser uma ocasião excitante ou também uma ocasião desagradável. Junto com aqueles que realmente estão encantados por estarem iniciando sua vida escolar, existem frequentemente outras crianças chorando ou pais tensos e nervosos. (BALABAN, 1988, p. 24).

Saberes Pedagógicos, Criciúma, v. 4, n¹, janeiro/abril 2020.- Curso de Pedagogia- UNESC 
Rapoport (2017) também fala sobre essa dificuldade que muitos pais têm, principalmente as mães, sobre essa inserção do filho na creche, e é comum nesse momento surgir sentimentos de insegurança e desconfiança. Assim, muitas vezes essa separação é mais dolorosa e difícil para os pais, do que para a própria criança.

Sabe-se que quando as crianças começam a frequentar a creche uma mistura de sentimentos está aflorando, mas, como elas estão muito ligadas aos pais, esses sentimentos são passados de um para o outro. Então, deve-se levar sempre em conta as emoções das crianças, mas nunca esquecer de que as emoções dos pais interferem nesse processo.

O papel dos pais nesse processo é essencial para que a adaptação da criança tenha sucesso. É necessário que a participação dos pais com a creche seja um envolvimento tranquilo e de complemento, já que os dois atuam em favor do bem-estar da criança. “[...] família e escola/creche, juntas, podem promover situações complementares e significativas de aprendizagem e convivência que realmente vão de encontro às necessidades e demandas das crianças e de ambas instituições.” (BHERING; DE NEZ, 2002, p. 63).

Muitos pais enfrentam diversas dificuldades até adquirirem confiança na instituição e, principalmente, no professor de seu filho. Para entender melhor essas desconfianças e medos que os pais sentem, Balaban (1988, p. 17) descreveu algumas perguntas comuns que os pais passam pensar:

[...] Será que o professor vai cuidar do meu filho? O professor vai compreendê-lo quando ele lhe fizer algum pedido? O professor gostará dele? O que o professor fará se o meu filho se comportar mal? Meu filho se rebaixará ou me enaltecerá na frente do professor? Meu filho revelará assuntos de família, que são particulares? O que acontecerá se meu filho se machucar na escola? Posso realmente confiá-lo a este professor? Essas perguntas desconfortáveis fazem com que alguns pais tenham dificuldades em entregar seu filho ou sua filha aos cuidados de um professor.

A escola deve estar preparada para esses tipos de questionamentos e dificuldades dos pais, que nos primeiros dias serão comuns. Por isso, a creche precisa ser um ambiente acolhedor e que possa utilizar estratégias que suavizem as preocupações apresentadas pela maioria dos familiares, pois a participação dos pais nesse processo é fundamental para que eles e seus filhos se sintam seguros nesse novo ambiente.

Saberes Pedagógicos, Criciúma, v. 4, nº1, janeiro/abril 2020.- Curso de Pedagogia- UNESC 
Passados alguns dias ou semanas, dependendo das reações das crianças, os pais começam a ver os resultados da adaptação, e se sentem mais confortáveis e confiantes frente ao professor. Na pesquisa de Balaban (1988, p. 21), os pais "usaram palavras tais como 'maravilhoso', 'confiante', 'aliviado', 'seguro', 'positivo', 'confortável' e 'ótimo'." para expressar seus sentimentos de felicidade em relação a essa adaptação.

Desta forma, pode-se perceber que para obter sucesso na adaptação da criança, é preciso que a creche forneça apoio aos familiares e seus filhos durante esse período, principalmente para os pais, pois nesse momento surgem sentimentos de insegurança e medo. Portanto, se a escola der esse apoio emocional que eles precisam, a adaptação terá maiores chances de ocorrer de forma mais tranquila. Por fim, para que haja um bom desenvolvimento da criança, é preciso que os pais depositem confiança nos professores, pois se espera que os mesmos sejam capacitados para isso. E que os pais tentem não passar seus medos e receios para seus filhos frente à adaptação, pois as crianças sentem essa insegurança, assim contribuindo com esse processo, fazendo que ele ocorra da melhor forma possível, passando confiança ao seu filho.

\section{METODOLOGIA, APRESENTAÇÃO E ANÁLISE DE DADOS}

A pesquisa analisou como a postura e a influência dos pais interfere no processo de adaptação de seus filhos na creche. Trata-se de uma pesquisa de natureza básica e de abordagem qualitativa. Nesse sentido, André e Ludke (1986) afirmam que a pesquisa qualitativa envolve o alcance dos dados descritivos obtidos na coleta de dados, sempre evidenciando mais o processo e as causas que as informações quantitativas, sempre se preocupando em descrever as perspectivas dos participantes da coleta.

Caracteriza-se também como uma pesquisa descritiva tendo como “[...] objetivo primordial a descrição das características de determinada população ou fenômeno ou, então, o estabelecimento de relações entre variáveis." (GIL, 2008, p. 42). Essa pesquisa qualificou-se como de campo, e teve como sujeitos pesquisados os pais, com filhos matriculados na Educação Infantil de uma escola particular do município de Criciúma/SC. Foram encaminhados vinte questionários e retornaram dezesseis. Embora não tenha sido determinado

Saberes Pedagógicos, Criciúma, v. 4, nº1, janeiro/abril 2020.- Curso de Pedagogia- UNESC 
como critério, dos dezesseis pesquisados, praticamente somente as mães responderam os questionários enviados aos familiares, apenas em um destes constatou-se que, em duas perguntas, um pai se manifestou, sendo que no mesmo questionário a mãe respondeu as demais. O questionário com dez perguntas estruturadas referentes a esse processo de adaptação escolar foi aplicado nas turmas do berçário I e II e infantil I, com familiares de crianças de zero a três anos de idade. A seleção dos pais foi realizada pela diretora, tendo como critério pais de crianças com maiores dificuldades de adaptação na escola.

Nesse estudo, optou-se pela análise de conteúdo com a criação de categorias com base nos objetivos desta pesquisa. "A categorização consiste na organização dos dados de forma que o pesquisar consiga tomar decisões e tirar conclusões a partir deles.” (GIL, 2008, p. 134).

Durante a análise foram utilizados os relatos na íntegra, conforme a escrita dos pais participantes dessa coleta de dados. 


\subsection{Perfil das mães participantes da pesquisa}

Para preservar os direitos e as questões éticas das entrevistadas, os seus nomes não foram revelados, mas para representá-las utilizaram-se as seguintes expressões: Mãe A, filha de 1 ano e 8 meses; Mãe B, filho de 5 meses; Mãe C, filha de 1 ano; Mãe D, filha de 2 anos e 8 meses; Mãe E, filha de 4 meses; Mãe F, filho de 1 ano e 11 meses; Mãe G, filho de 7 meses; Mãe H, filha de 9 meses; Mãe I, filho de 1 ano e 10 meses; Mãe J, filha de 4 meses; Mãe K, filha de 6 meses; Mãe L, filha de 1 ano e 2 meses; Mãe M, filha de 2 anos e 6 meses; Mãe N, filha de 1 ano; Mãe O, filha de 1 ano e 3 meses; Mãe P, filho de 1 ano e 5 meses. A idade das crianças é referente ao período que iniciaram o processo de adaptação na creche.

O quadro a seguir apresenta o perfil das mães que participaram da pesquisa destacando a formação, a situação de trabalho e a quantidade de filhos. Também, o perfil das crianças em relação à turma, idade e sexo.

\section{Quadro 1: Perfil das mães participantes}

\begin{tabular}{|c|c|c|c|}
\hline \multirow{2}{*}{ MÃES } & FORMAÇÃO & TRABALHO & QUANTIDADE DE FILHOS \\
\hline \multirow{2}{*}{ CRIANÇAS } & $\begin{array}{c}\text { Ensino Superior: 10 } \\
\text { Pós-graduação: } 5\end{array}$ & $\begin{array}{c}\text { 14 mães trabalham } \\
\text { 2 não trabalham }\end{array}$ & $\begin{array}{c}\text { 13 são filhos únicos } \\
3 \text { tem irmãos }\end{array}$ \\
\cline { 2 - 4 } & $\begin{array}{c}\text { Berçário I: } 4 \\
\text { Terçário II: } 5 \\
\text { Infantil I: } 7\end{array}$ & IDADE & SEXO à 3 anos \\
\hline
\end{tabular}

Fonte: Dados de pesquisa (2018)

\subsection{Motivações da inserção dos filhos na Educação Infantil}

Inicialmente, procurou-se conhecer os principais motivos que os pais levam a matricularem seus filhos na Educação Infantil. Dentre as participantes, nove responderam que foi por causa das necessidades laborais dos pais, ou seja, porque trabalham, e também devido à inserção da criança na creche para a sua socialização e desenvolvimento. Destaca-se aqui a 
fala de uma das mães: "Por 2 motivos: socialização e brincar com outras crianças e para poder trabalhar." (MÃE A).

Porém, cinco mães relataram que o motivo maior foi por causa da socialização, desenvolvimento e interação de seu filho com as demais crianças, conforme o relato: "Para a interação com as crianças e para um melhor desenvolvimento.” (MÃE P). Já outras duas mães disseram que o motivo foi devido à volta ao trabalho: "Retorno do trabalho.” (MÃE G).

Constatou-se, então, por meio dessa pesquisa, que os principais fatores que influenciam no processo da matrícula de crianças na creche são devido à necessidade do retorno ao trabalho, e pela socialização e desenvolvimento da criança. Essa afirmação vai ao encontro do que Rapoport (2017) fala sobre motivos que levam os pais a colocarem a criança na creche. A referida autora afirma que muitos pais têm diversos motivos, dois deles apresentados são do retorno ao trabalho, e também devido a importância da socialização das crianças com as demais.

\subsection{A importância de conhecer a creche e dialogar com a criança sobre a sua nova fase}

Levar a criança para conhecer o novo ambiente escolar antes de iniciar seu processo de adaptação é importante para que ela possa começar a ter contato com a creche (RAPOPORT, 2017). Das dezesseis participantes, onze relataram ter levado a criança no momento da visita para conhecer o ambiente escolar. De acordo com o relato, "Como ela era muito bebê não houve muita conversa, mas ela e eu conhecemos a escolinha antes da matrícula." (MÃE H). Porém, as demais participantes disserem que a criança só conheceu a escola no momento da adaptação. Isso se confirma no relato a seguir "Ele tinha apenas 5 meses, mas sempre conversei sobre a ida na escolinha e como seria legal fazer novos amigos. O primeiro contato dele foi na adaptação.” (MÃE B).

Desta forma, com essa pesquisa, pôde-se perceber que a maioria dos pais entende a importância de a criança ir visitar o novo ambiente com eles. Esses relatos confirmam o que Rapoport (2017) e Worst (2016) falam sobre o momento em que os pais vão fazer a entrevista nas creches, pois elas recomendam que a criança vá junto para que possa ter contato com o

Saberes Pedagógicos, Criciúma, v. 4, nº 1, janeiro/abril 2020.- Curso de Pedagogia- UNESC 


\section{SABERES PEDAGÓGICOS}

Revista do Curso de Graduaçāo de Pedagogia - Unesc

ISSN 2526-4559

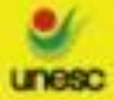

totinaing

novo ambiente escolar e para que possa começar a se acostumar com os demais colaboradores da creche.

Além de conhecer o novo ambiente escolar, é preciso que os pais tenham um diálogo com seus filhos sobre esse novo processo. Por este motivo, quando questionadas sobre esse momento da conversa, a maioria das participantes respondeu que conversaram com seus filhos sobre a inserção na creche, apesar de algumas mães relatarem que as crianças eram muito pequenas quando iniciaram a adaptação, conforme relato "Sim, mesmo ele tendo 7,5 meses antes do ingresso à escola conversávamos sobre a inclusão na escolinha. Quando fomos conhecer as escolas ele esteve presente.” (MÃE G). Porém, cinco mães disseram não ter feito esse momento de conversa com seu filho, conforme afirmação: "Não ocorreu esta conversa, pois ela tinha apenas 6 meses." (MÃE K).

Ter esse momento de diálogo com a criança antes de ela iniciar sua adaptação é importante para que ela comece a entender que vai para a creche, mesmo que ainda seja muito pequena, pois ela pode compreender o que seus pais estão tentando explicar. Balaban (1988) diz que uma das preparações com esse novo período é que os pais tenham uma conversa com seus filhos antes de iniciar a sua adaptação, explicando a eles que a creche é um lugar que tem muitas crianças, que elas vão para lá para poder brincar e aprender, além de comer e descansar. Sempre lembrando os seus filhos que no final do dia os pais vão buscá-los e que eles irão para casa.

\subsection{Duração do período de adaptação e dificuldades}

Notou-se uma diversidade de respostas referente à duração do período de adaptação, o processo mais rápido durou três dias, mas também teve situações que levaram três meses. Vale lembrar que, cada criança é diferente uma da outra, e que cada processo de adaptação será particular, influenciando na sua duração (WORST, 2016).

Esse processo de adaptação, muitas vezes, passa por algum tipo de obstáculo, quando questionadas sobre as maiores dificuldades que ocorreram neste período, três mães relataram que foi a sua própria adaptação, uma delas disse: "A minha adaptação, eu sofria

Saberes Pedagógicos, Criciúma, v. 4, nº1, janeiro/abril 2020.- Curso de Pedagogia- UNESC 
muito em deixá-la na escola, ela chorava e eu chorava junto, me sentia culpada, tinha a 'crença' de que ela ficaria melhor ao meu lado o tempo todo.” (MÃE C).

Já as demais mães relataram outros fatores como, o choro, a despedida, a rotina nova e o desmame. Dessas, oito mães relataram que a despedida muitas vezes junto com o choro foi a maior dificuldade, conforme apresentado no relato: "A despedida sempre. Logo após a despedida, ao chegar na sala e ver a professora e os amigos ele já se tranquilizava." (MÃE I). Outras apresentaram o desmame como um fator principal, como no relato: "Por ter colocado meu filho com 5 meses e meio na escola, ele ainda só mamava no peito. A dificuldade foi na introdução da mamadeira no período da tarde. No começo ele não aceitava. Depois com a troca do tipo de mamadeira e em torno de 1 semana ele aceitou." (MÃE B).

Apareceu como dificuldade também a introdução à nova rotina, conforme mostra o relato: "Em ficar na escola e a mãe ter que sair. Se adaptar com uma nova rotina escolar, pois em casa ela tinha outra rotina.” (MÃE A). Apesar de todas essas dificuldades particulares enfrentadas pelos pais, duas mães relataram não terem dificuldades, conforme afirmação: "Acredito que não houve dificuldades, se adaptou bem." (MÃE J). Por fim, dentre todas essas dificuldades, uma mãe relatou que: "O pai, o apego com a filha e a preocupação embora ela estava bem.” (MÃE K).

Percebeu-se, então, que diversos fatores podem interferir no processo de adaptação de uma criança na creche, conforme os relatos citados. Essas dificuldades nesse período são comuns para muitos pais que enfrentam essa nova fase. Portanto, os relatos dessas mães vão ao encontro do que Balaban (1988) fala sobre o que os pais podem sentir nesse momento. Os mesmos estão intimamente ligados com seus filhos. Por este motivo, todos os seus sentimentos, querendo ou não, são passados de um para o outro. Desta forma, se os pais não se sentirem confiantes nesse processo, podem acabar afetando seus filhos, ocorrendo, assim, a reação mais esperada pela criança, o choro no momento da despedida.

\subsection{Pensamentos dos pais frente à adaptação e suas emoções}

Entender os pensamentos dos pais nessa fase é muito importante, pois a creche e seus colaboradores podem auxiliar nesse momento que é de suma importância. Portanto,

Saberes Pedagógicos, Criciúma, v. 4, n¹, janeiro/abril 2020.- Curso de Pedagogia- UNESC 


\section{SABERES PEDAGÓGICOS}

Revista do Curso de Graduaçāo de Pedagogia - Unesc

ISSN $2526-4559$

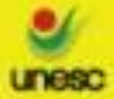

wationstion

buscou-se entender os principais pensamentos dos pais antes e após deixar seus filhos na creche. Das dezesseis participantes, quatro mães relataram estar se sentindo confiantes e positivas com essa inserção, como no relato: "Só pensava que seria algo melhor para ele e para a evolução dele. Sempre soube que estava sendo bem cuidado.” (MÃE I).

Porém, a maioria das mães falou que estava com grandes dúvidas e perguntas, uma delas relatou: "Será que elas vão tratar bem minha filha? Será que vão atender suas necessidades com tanta criança junto? Após deixá-la: pensei, preciso confiar!” (MÃE D). Outra mãe também relatou suas preocupações "Antes, a criança vai sofrer, eu vou perder a 'infância' da minha filha, ela vai ficar jogada esperando passar o período até eu ir buscá-la. Após, pensei que ela fica feliz na escolinha, ela brinca bastante, ela tem contato com mais pessoas e fica mais esperta.” (MÃE C). Já o pai ressaltou que: “Antes: estou abandonando minha filha? Após: é importante para minha filha esse convívio e ela fica feliz." (PAI/MÃE $\mathrm{K})$.

Portanto, notou-se que por mais que os pais saibam que os seus filhos precisam passar por aquele momento e que é difícil para eles essa separação, ter dúvidas de que se está fazendo o certo é comum e normal nesse momento. Isso se confirma ainda com o que Balaban (1988) fala que esses pensamentos são normais para muitos pais, pois eles ficam o tempo todo se fazendo perguntas, mas que com o passar de algumas semanas, esses pensamentos vão mudando dia após dia, transformando-se em pensamentos positivos. Com o tempo, eles vão vendo que seus filhos estão felizes naquele ambiente e, consequentemente, eles também se sentem confiantes.

Como mostram os relatos posteriores à adaptação, todos afirmaram que se sentiram confiantes e certos de sua escolha: "Antes: como ele ficaria sem estar conosco? Quais suas reações? Se choraria muito? Após: estávamos bem seguros e certos de que seria para o bem dele. Então foi tranquilo.” (MÃE F).

Desta forma, no início dessa adaptação, os pais passam por uma mistura de sentimentos, ocorrendo algumas reações emocionais, a maioria das mães relatou que choraram, pois se sentiam culpadas e preocupadas, pois não sabiam como seus filhos ficariam sem elas, de acordo com o relato: "Chorei 2 semanas todos os dias, por medo. Depois passou." (MÃE E). Já o pai relatou que: "Eu trabalhava o dia inteiro preocupado, olhando o

Saberes Pedagógicos, Criciúma, v. 4, n¹, janeiro/abril 2020.- Curso de Pedagogia- UNESC 
celular para ver se a escolinha tinha me ligado.” (PAI/MÃE K). Isto mostra que alguns pais, ao seu modo, demostram preocupação e insegurança durante este processo de adaptação.

Contudo, quatro mães relataram estarem confiantes e seguras da opção de colocar seu filho na creche desde o início: "Senti que havia tomado a decisão correta. Estava segura com a escola. Claro que dá um aperto no coração, mas nada exagerado. Tentei passar segurança para minha filha." (MÃE L).

Portanto, pode-se notar que esses sentimentos que os pais apresentam são comuns nesse processo, pois estão entregando seus filhos a um espaço inicialmente desconhecido, então o choro aparece como uma forma de tristeza pela parte dos pais. Porém, alguns se sentem mais seguros da decisão que foi tomada e mais tranquilos com esse processo. Isso ocorreu também na pesquisa feita por Balaban (1988) e Rapoport (2017), em que se pode observar que ao mesmo tempo em que muitos pais tendem a se sentir culpados e inseguros com o ingresso de seus filhos na creche, outros estavam totalmente confiantes da decisão tomada.

Em seguida, as mães tiveram que responder como elas lidaram com essas reações emocionais desconfortáveis, se fizeram alguma coisa ou tentaram amenizá-las. Sete participantes relataram que confiavam na escola ou que mantinham contato com a diretora sobre o andamento da adaptação conforme relato: "Conversei muitas vezes na escola procurando saber como agir e como ela estava na escola. A atitude e confiança que a professora e escola passaram foi fundamental." (MÃE M). Já outra mãe relatou que "Durante a semana de adaptação trocava mensagens por whatsapp com a diretora para saber se ela estava tranquila, se não estava chorando. Eu sempre recebia retorno, fotos e vídeos. Isso me deixava tranquila." (MÃE L).

Outras participantes relataram que esse momento iria passar, buscavam ter pensamentos positivos e, também com a ajuda do trabalho, elas se ocupavam mais, tentando não pensar muito nos seus filhos: "Procurei entender que mais cedo ou mais tarde, este dia chegaria, e que é necessário para ela e para eu, este processo de separação por algumas horas. E que faz 'muito bem' pra gente este tempo separadas." (MÃE D). Outra mãe relatou que "Trabalhando foi mais fácil, me ocupava e o tempo passava rápido para buscá-la e ver que estava tudo bem. Mesmo antes de matricular ela eu já me policiava e amadurecia a ideia da

Saberes Pedagógicos, Criciúma, v. 4, nº1, janeiro/abril 2020.- Curso de Pedagogia- UNESC 


\section{SABERES PEDAGÓGICOS}

Revista do Curso de Graduaçāo de Pedagogia - Unesc

ISSN $2526-4559$

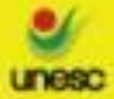

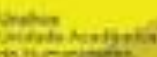

minha volta ao trabalho e em deixá-la na escola." (MÃE H). E apenas uma mãe relatou que "Nada." (MÃE K), baseada em sua resposta anterior, se ocupava muito no trabalho para não pensar na filha.

Tentar amenizar essas emoções nem sempre é fácil para os familiares, porém, manter o equilíbrio e saber que a criança está bem é fundamental, pois, assim, esses pensamentos vão passando. Se ocupar com o trabalho é uma maneira que pode ajudar a amenizar esses pensamentos, mas também como relatado, o auxílio da escola nesse momento é um suporte muito importante para a família. Rapoport (2017) fala sobre essa importância que algumas mães relataram sobre se sentiram confiantes com esse apoio da escola, pois esta comunicação é um papel que a creche deve ter com os pais para mantê-los mais seguros e tranquilos, auxiliando assim aqueles que ainda se sentem inseguros com essa nova fase.

Desta forma, depois de questionadas sobre como tentar amenizar suas reações, as participantes tiveram que responder se essas reações reduziram com o tempo ou permanecem até hoje. Grande parte das participantes relatou que essas reações reduziram e até sumiram após esse período de adaptação, conforme relato: "Reduziram, confio 100\% que ela está bem e é feliz lá." (MÃE N), outra mãe relatou que "Sumiram completamente. Ela ama ir e eu fico tranquila com tudo lá." (MÃE M).

Além desses relatos, houve duas respostas distintas, pois uma mãe disse que "Agora só tenho estas reações quando ela está doente, mas graças sempre foi muito tranquila." (MÃE J). Já outra mãe relatou que: "Reduziram com o tempo. Só volto pra casa chateada quando vou deixá-lo na escola e ele chora. Um ponto interessante da escola que meu filho está, é que me mandam fotos do (citou o nome do filho) brincado feliz para me tranquilizar, caso ele tenha chorado quando deixei ele lá.” (MÃE B).

Por fim, pode-se constatar que para os pais todas essas reações vão sumindo gradativamente quando seus filhos começam a se sentir seguros e felizes naquele novo ambiente. Conforme Balaban (1988) mostra em sua pesquisa, a maioria dos pais relatam que esses sentimentos foram passando e se tornando um grande alívio para eles, pois viram que seus filhos começaram a ficar felizes naquele ambiente e, consequentemente, os pais também ficavam, mostrando assim que essa adaptação ocorre de forma gradativa.

Saberes Pedagógicos, Criciúma, v. 4, nº1, janeiro/abril 2020.- Curso de Pedagogia- UNESC 


\subsection{A importância das orientações dos profissionais da creche}

Ter o auxílio da creche nesse momento de extrema aflição para os pais é fundamental, pois eles precisam saber como lidar e como administrar esse processo. É comum ter esses receios, principalmente para os familiares, pois estão deixando seus filhos num ambiente novo, com pessoas desconhecidas, portanto é imprescindível que a escola sempre esteja disponível para que os pais possam tirar suas dúvidas, pois, assim, eles se sentem mais seguros e sabem que podem contar com o total apoio da creche. (BHERING; DE NEZ, 2002).

Das dezesseis participantes, todas responderam que tiveram orientações dos profissionais da escola. Três mães relataram que tiveram orientações de como entregar seus filhos ao professor, como no relato: "Sim, conversaram muito conosco. Orientaram a entregar o nosso filho de frente e de costas para o pai e a mãe. Sempre falava: Mamãe vai para o trabalho, mas logo volta!” (MÃE G). Por outro lado, algumas mães relataram que foram orientadas sobre o horário reduzido, conforme relato: "Sim, fui muito bem orientada. Iniciamos um pouco de horas por dia até o ambiente não ser estranho para ela se sentir segura, sempre me despedindo afirmando que voltava para buscá-la e isso foi funcionando muito bem.” (MÃE O).

Já outras mães relataram que tiveram orientações e conversas que auxiliaram nesse processo, tais como: "Sim!!! Sem elas eu não teria conseguido. Acredito que teria desistido. Como pensei em desistir várias vezes. O processo foi bem difícil. Minha filha foi bem resistente. Sou muito grata por cada ajuda e instrução que me foi dada.” (MÃE D). Outra ainda relatou: "Sim. A orientação da escola ajudou muito. Ex.: tratar com naturalidade, não ficar 'alimentando' o choro, afirmar nosso amor e que sempre voltamos pra buscá-la. Enfim, orientações e suporte emocional." (MÃE M).

$\mathrm{O}$ apoio da creche é essencial para que os pais possam se sentir mais seguros e confiantes nesse processo, portanto é preciso existir disponibilidade para que os familiares possam tirar suas dúvidas a qualquer momento. Bhering e De Nez (2002) chamam atenção para a importância da boa relação entre a família e a creche, pois essa troca de informações

Saberes Pedagógicos, Criciúma, v. 4, nº1, janeiro/abril 2020.- Curso de Pedagogia- UNESC 


\section{SABERES PEDAGÓGICOS}

Revista do Curso de Graduaçūo de Pedagogia - Unesc

ISSN 2526-4559

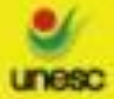

Thtiming

unesc

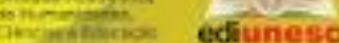

gera nos pais confiança e segurança na escola. Quando ambos têm essa boa relação, eles favorecem o desenvolvimento da criança e agem em favor do sucesso dela.

\subsection{Contribuição dos pais na adaptação de seus filhos}

O papel dos pais nesse processo é fundamental para que seu filho tenha uma adaptação mais tranquila. As participantes tiveram que responder de que forma elas poderiam ter contribuído para que a adaptação do seu filho ocorresse de maneira mais tranquila. Grande parte das participantes relatou que a adaptação foi tranquila, que não mudariam, pois fizeram tudo que podiam, conforme relato: "Acho que tudo que podíamos foi feito. Não vejo o que fazer diferente. Acho que demorou por ser o tempo que ela precisava para entender a mudança na rotina.” (MÃE M).

Algumas mães relataram outros pontos, como: "Conhecimento e informação, temos muitas crenças que se desmistificam com a experiência vivida, com o conhecimento e a informação.” (MÃE C). Já outra participante destacou: “Acredito que a adaptação de cada criança é imprevisível. Achava que meu filho seria mais tranquilo, mas não foi. Acredito que a conversa contribui muito.” (MÃE I).

Por fim, pode-se notar que, por mais que os pais se sintam ansiosos com essa nova fase, eles alegaram que fizeram tudo o que podiam para que esse processo ocorresse de maneira mais tranquila possível, sempre passando segurança para seus filhos. Assim, Balaban (1988) e Rapoport e Piccinini (2001) dizem que os pais precisam entender que esse momento é muito importante para o seu filho, por isso podem contribuir de forma que mantenha a calma, principalmente no momento da despedida, transferindo sempre o máximo de segurança, pois assim ele irá se sentir mais confiante naquele novo ambiente.

Lembrando que todas as categorias analisadas podem contribuir para que os pais se sintam mais confiantes e depositem realmente confiança na creche, pois, desse modo, eles irão transferir seus sentimentos para seus filhos, que serão de máximo conforto em relação à creche, amenizando assim o desconforto no momento da separação entre pai e filho. 


\section{SABERES PEDAGÓGICOS}

Revista do Curso de Graduaçāo de Pedagogia - Unesc

ISSN 2526-4559

\section{CONCLUSÃO}

Esta pesquisa possibilitou o aprofundamento teórico e prático sobre as experiências dos familiares no período de adaptação da criança na creche. Para tal alcance, teve como objetivo geral analisar a participação e reação dos pais no período de adaptação de seus filhos na creche. Assim, para conseguir alcançar esse objetivo, foram feitas pesquisas bibliográficas e questões por meio de questionário. Percebeu-se neste sentido que os pais interferem na adaptação dos seus filhos, principalmente por meio de suas reações. Com base na pesquisa realizada, notou-se que a maioria teve dificuldades em deixar seus filhos na escola, porém, com o tempo, esses sentimentos amenizaram ou até se extinguiram.

Em relação a trajetória histórica da Educação Infantil, foram realizadas leituras prévias para descrever como ocorreu esse processo. O mesmo aconteceu em relação ao objetivo de verificar a finalidade da Educação Infantil na legislação em que foram realizadas outras leituras em que se pode perceber que a mesma é garantida por meio de documentos, e que as crianças têm direito ao ingresso na educação infantil.

Sobre as dificuldades enfrentadas pelos pais ao deixarem seus filhos na creche, percebeu-se que a grande maioria teve diversas dificuldades principalmente por conta dessa separação entre pais e filho, outras mães apresentaram como motivo a sua própria adaptação em relação a essa nova fase, mas teve também o choro, a despedida, o desmame e a adequação em relação a nova rotina. Tudo isso influenciou na adaptação dos pais e também na dos filhos durante esse processo, principalmente no início, até gerar confiança na creche.

Apontar como os pais podem auxiliar na adaptação de seus filhos e, com base nos questionários aplicados, percebeu-se que eles podem contribuir com essa adaptação, como apareceu nos relatos, pois muitos disseram que fizeram tudo que podiam, mas que passar segurança e confiança para o filho é essencial para que a criança comece a ter segurança na creche.

Quanto a discutir a importância da adaptação escolar para a aprendizagem/desenvolvimento da criança, pôde-se notar que a adaptação escolar é uma fase muito importante para a criança, mas para que esse processo seja alcançado, um fator relevante e essencial é que se tenha sempre esse diálogo constante entre pais e creche, pois

Saberes Pedagógicos, Criciúma, v. 4, nº 1, janeiro/abril 2020.- Curso de Pedagogia- UNESC 


\section{SABERES PEDAGÓGICOS}

Revista do Curso de Graduaçāo de Pedagogia - Unesc

ISSN 2526-4559

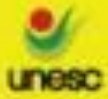

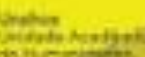

para que ocorra o sucesso da criança em sua aprendizagem e desenvolvimento é necessário que a adaptação seja tranquila. Assim, ocorrerá se os familiares e a creche tiverem uma boa relação, principalmente o apoio da creche com os pais para mantê-los seguros e certos da decisão tomada.

Desta forma, notou-se, então, que os objetivos foram alcançados e que realmente os pais, mesmo sem perceber, acabam interferindo na adaptação de seus filhos, principalmente por meio das suas reações. Todavia, eles entendem que esse processo é importante para o desenvolvimento de todos, pois precisam passar o máximo de segurança e confiança para a criança, por mais que os próprios pais ainda tenham sentimentos de desconfiança e medo do novo.

Assim, sugere-se que sejam feitas reuniões com os familiares antes de iniciar essa adaptação para que possam esclarecer suas dúvidas e amenizar seus medos. Que essas conversas permaneçam durante esse processo, bem como a creche esteja sempre disponível para que os pais possam dialogar com eles a qualquer momento, demonstrando afeto e preocupação com os mesmos, pois mostra que a instituição se preocupa com o bem-estar da família e da criança.

Por fim, percebeu-se, então, que alguns pais inseguros podem afetar a adaptação de seus filhos, mas a maioria consegue superar conforme o acolhimento da escola e por isto ter uma boa relação entre eles é essencial para o sucesso da criança. Desta forma, esta pesquisa visou contribuir de maneira que a creche consiga entender melhor os medos e receios dos familiares, podendo auxiliá-los de maneira que se sintam mais seguros e confiantes. Este estudo também pode fornecer informações e auxílio para os pais que se mostram preocupados com essa nova fase.

\section{REFERÊNCIAS:}

ARIÈS, Philippe. História social da criança e da família. 2. ed. Rio de Janeiro: LTC, 1981.

BALABAN, Nancy. O início da vida escolar: da separação à independência. Porto Alegre: Artes Médicas, 1988. 
BHERING, Eliana; DE NEZ, Tatiane Bombardelli. Envolvimento de pais em creche: possibilidades e dificuldades de parceria. 2002. 10f. Programa Institucional de Bolsas para Iniciação Científica - Universidade do Vale do Itajaí, Itajaí, 2000. Disponível em: <http://www.scielo.br/scielo.php?script=sci_arttext\&pid=S0102-37722002000100008>. Acesso em: 14 abr. 2018.

BRASIL. Lei de diretrizes e bases da educação nacional: Lei número 9394, 20 de dezembro de 1996. Disponível em: < http://www.planalto.gov.br/ccivil_03/LEIS/19394.htm>. Acesso em: 28 abr. 2018.

. Ministério da Educação. Base Nacional Comum Curricular - BNCC. $2^{\mathrm{a}}$ versão. Brasília, DF, 2016. Disponível em:

<http://basenacionalcomum.mec.gov.br/wpcontent/uploads/2018/06/BNCC_EI_EF_110518_ versaofinal_site.pdf $>$. Acesso em: 13 out 2018.

GIL, Antonio Carlos. Como elaborar projetos de pesquisa. 4. ed. São Paulo: Atlas, 2008.

HADDAD, Lenira. A creche em busca de identidade. 3. ed. São Paulo: Edições Loyola, 2002.

LÜDKE, Menga; ANDRÉ, Marli E. D. A. Pesquisa em educação: abordagens qualitativas. 2. ed. São Paulo: E.P.U, 1986.

PAPALIA, Diane E; FELDMAN, Ruth Duskin. Desenvolvimento humano. Porto Alegre: Artmed, 2013.

RAPOPORT, Andrea. A importância do período de adaptação. In: RAPOPORT, Andrea et al. O dia a dia na educação infantil. 3. ed. Porto Alegre: Mediação, 2017.

PICCININI, Cesar Augusto. O ingresso e adaptação de bebês e crianças pequenas à creche: alguns aspectos críticos. 2001. 14f. Dissertação (Mestrado em Psicologia) Universidade Federal do Rio Grande do Sul, Porto Alegre, 2000. Disponível em: <http://www.scielo.br/scielo.php?script=sci_arttext\&pid=S0102-79722001000100007>. Acesso em: 15 abr. 2018.

FARIAS, Mabel. Infância e educação no Brasil nascente. In: VASCONCELLOS, Vera Maria Ramos de (Org.). Educação da infância: história e política. Rio de Janeiro: DP\&A, 2005.

WORST, Lariza. Adaptação de Bebês na Educação Infantil. Revista Eventos Pedagógicos, Mato Grosso, v. 7, n. 2, p. 469-485, jun./jul. 2016. Disponível em: <http://sinop.unemat.br/projetos/revista/index.php/eventos/article/view/2242/1745>. Acesso em: 15 abr. 2018. 